\title{
Isolation and culture of umbilical vein mesenchymal stem cells
}

\author{
D.T. Covas ${ }^{1,2}$, \\ J.L.C. Siufi ${ }^{1}$ \\ A.R.L. Silva ${ }^{1}$ and \\ M.D. Orellana ${ }^{1}$
}

\author{
${ }^{1}$ Centro de Terapia Celular (CEPID-FAPESP), Fundação Hemocentro de Ribeirão Preto, \\ Centro Regional de Hemoterapia, Hospital das Clínicas, Faculdade de Medicina de \\ Ribeirão Preto, Universidade de São Paulo, Ribeirão Preto, SP, Brasil \\ ${ }^{2}$ Divisão de Hematologia e Hemoterapia, Departamento de Clínica M édica, \\ Faculdade de Medicina de Ribeirão Preto, Universidade de São Paulo, \\ Ribeirão Preto, SP, Brasil
}

\section{Correspondence \\ D.T. Covas \\ Fundação Hemocentro de \\ Ribeirão Preto \\ Av. Tenente Catão Roxo, 2501 \\ 14051-140 Ribeirão Preto, SP \\ Brasil \\ E-mail: dimas@ fmrp.usp.br \\ Research supported by FAPESP, CNPq and FUNDHERP.}

Received March 2, 2003 Accepted July 14, 2003

\section{Abstract}

Bone marrow contains a population of stem cells that can support hematopoiesis and can differentiate into different cell lines including adipocytes, osteocytes, chondrocytes, myocytes, astrocytes, and tenocytes. These cells have been denoted mesenchymal stem cells. In the present study we isolated a cell population derived from the endothelium and subendothelium of the umbilical cord vein which possesses morphological, immunophenotypical and cell differentiation characteristics similar to those of mesenchymal stem cells isolated from bone marrow. The cells were isolated from three umbilical cords after treatment of the umbilical vein lumen with collagenase. The cell population isolated consisted of adherent cells with fibroblastoid morphology which, when properly stimulated, gave origin to adipocytes and osteocytes in culture. Immunophenotypically, this cell population was found to be positive for the CD29, CD13, CD44, CD49e, CD54, CD90 and HLA-class 1 markers and negative for CD45, CD14, glycophorin A, HLA-DR, CD51/61, CD106, and CD49d. The characteristics described are the same as those presented by bone marrow mesenchymal stem cells. Taken together, these findings indicate that the umbilical cord obtained from term deliveries is an important source of mesenchymal stem cells that could be used in cell therapy protocols.
Bone marrow (BM) contains a special population of stem cells able to support hematopoiesis and to differentiate into different cell lines (adipogenic, osteogenic, chondrogenic, myogenic, and cardiomyogenic lines) (1,2). These cells were first described in 1974 by Friedenstein et al. (3), who characterized them as fibroblastic stem cells capable of forming colonies (fibroblast colonyforming units, CFU-F). The CFU-F designa-

\section{Key words}

- Mesenchymal stem cells

- U mbilical vein

- Adipocytes

- O steocytes

- Cell differentiation tion was later replaced by stromal BM fibroblasts (4) and today these cells are called mesenchymal stem cells (MSC) (5). Operationally, this cell population derived from mononuclear BM cells is composed of cells adhering to the culture plate when cultivated in classical culture medium supplemented only with fetal calf serum. These cells have a fibroblastoid morphology, a high replicative capacity and, after an appropriate stimulus, 
they can differentiate into at least seven cell types, i.e., osteocytes, chondrocytes, adipocytes, tenocytes, myotubules, astrocytes, and stromal cells able to support hematopoiesis (6).

In addition to being present in BM, MSC have been demonstrated to occur in various organs and in the circulating blood of preterm fetuses, where they circulate together with hematopoietic stem cells $(7,8)$. The presence of MSC in umbilical cord blood of term infants is a controversial topic (9). Wexler et al. (10) concluded that umbilical cord blood and peripheral blood with stem cell mobilization do not contain MSC.

The objective of the present investigation was to determine the presence of MSC in the vascular endothelium of the umbilical cord vein of infants born at term. Thus, three umbilical cords were obtained from term deliveries after each mother signed a donation form according to a protocol approved by the Research Ethics Committee of HCRPUSP. The umbilical vein was catheterized and washed twice internally with $1 \mathrm{X}$ PBS and its distal end was clamped. The vein was then filled with a $1 \%$ collagenase solution (Sigma, St. Louis, MO, USA) in PBS and the proximal end was occluded. After incubation at $37^{\circ} \mathrm{C}$ for $20 \mathrm{~min}$, the collagenase solution was drained and the cells of the endothelial and subendothelial layers were collected by washing with PBS. The cell suspension was centrifuged at $400 \mathrm{~g}$ and the cell pellet was resuspended in 199 growth medium (Sigma) supplemented with 20\% fetal calf serum (HyClone, Logan, UT, USA), 2 mM L-glutamine (Gibco-BRL, Gaithersburg, MD, USA), $100 \mathrm{U}$ penicillin/streptomycin (Sigma), $1 \mathrm{X}$ endothelial cell growth factor (Sigma), and $10 \mathrm{ng} / \mathrm{ml}$ vascular endothelial growth factor (Sigma). Next, the cells were counted and plated onto $25-\mathrm{cm}^{2}$ culture bottles (Cellstar, Greiner, Germany) at the concentration of $10^{5} / \mathrm{ml}$. After 4 days of culture the medium was changed and nonadherent cells were removed. After 3 weeks with weekly medium changes, fibroblastoid cells became the predominant cells in culture. At that time the culture medium was replaced with $\alpha$-MEM (Gibco) supplemented with $20 \%$ fetal calf serum (HyClone), $2 \mathrm{mM}$ L-glutamine (Gibco), and $100 \mathrm{U}$ penicillin/streptomycin (Sigma). When the cells reached confluence they were trypsinized (5 $\mathrm{mg}$ trypsin/ml PBS), washed in PBS, resuspended in $20 \mathrm{ml}$ medium, and replated onto $75-\mathrm{cm}^{2}$ bottles (Cellstar) for expansion. After expansion, the cells were trypsinized again and analyzed with a flow cytometer (FACsort, BD, San Jose, CA, USA). The following monoclonal antibodies were used: CD13PE, CD14-PE, CD29-PE, CD49d-PE, CD49ePE, CD54-PE, CD106-PE, glycophorin-PE, CD44-FITC, CD45-FITC, CD51/61-FITC, CD90-FITC, HLA-class 1-FITC, and HLADR-FITC (Pharmingen, San Diego, CA, USA).

Assays of adipogenic and osteogenic differentiation were performed after the third cell passage by plating $10^{4}$ cells onto 3.6 $\mathrm{cm}^{2}$ plates. The stimulus for adipogenic differentiation consisted of culture for 15 to 21 days in $\alpha$-MEM medium supplemented with $10 \mu \mathrm{g} / \mathrm{ml}$ insulin (Novo Nordisk, São Paulo, SP, Brazil), $100 \mu \mathrm{M} / \mathrm{ml}$ indomethacin (Sigma), and $1 \mu \mathrm{M} / \mathrm{ml}$ dexamethasone (Sigma). Osteogenic differentiation was induced for 3 weeks with $\alpha$-MEM medium supplemented with $200 \mu \mathrm{M} / \mathrm{ml}$ ascorbic acid (Sigma), $0.1 \mu \mathrm{M} / \mathrm{ml}$ dexamethasone and 10 $\mathrm{mM} / \mathrm{ml}$ B-glycerophosphate. In both cultures the medium was changed twice a week. The effectiveness of differentiation was assessed by histochemical staining. For adipocyte identification the cells were fixed in $10 \%$ formol for $30 \mathrm{~min}$ and stained with Sudan III for $1 \mathrm{~min}$. Osteocytes were identified after fixation with an ice-cold solution of absolute methanol and $33 \%$ formaldehyde $(9: 1, \mathrm{v} / \mathrm{v})$ and by silver nitrate staining for the identification of hydroxyapatite crystals (von Kossa) and alkaline phosphatase. Control cultures without the differentiation stimuli were car- 
ried out in parallel to the experiments and stained in the same manner.

After $24 \mathrm{~h}$ of culture, two types of adherent cells were observed: a more numerous cell population consisting of small flattened cells morphologically similar to the endothelial cells (human umbilical vein endothelial cells), and a population consisting of a few spindle-shape fibroblastoid cells preliminarily identified as MSC. After 1 week of culture, these MSC became the predominant cell type. After the second cell passage the MSC cultures appeared to be homogeneous and with a high replicative potential. This potential remained unchanged over 20 cell passages when the cells were cultured and maintained at low concentrations. When they reached high confluence, the cells lost their replicative potential and presented morphological changes.

In the cytometric analysis, MSC did not present labeling for the hematopoietic line (CD45-, CD14-, glycophorin A-) or for HLADR, CD51/61, CD106 (VCAM-1), and CD49d (integrin $\alpha 4$ ) and were positive for the following adhesion molecules: CD29 (integrin B1), CD13 (aminopeptidase), CD44 (H-CAM), CD49e (integrin $\alpha 5$ ), CD54 (ICAM-1), CD90 (Thy 1), and HLA-class 1 (Figure 1).

MSC culture in adipogenic differentiation medium led to the appearance, after 7 days, of larger rounded cells presenting numerous fat vacuoles in the cytoplasm visualized by Sudan III staining. The number of these cells increased continuously up to the 20th day of culture and remained stable for more than two months of culture (Figure 2).

The osteogenic stimulus of MSC led to the appearance, after 15 days of culture, of refringent crystals on the cells, better visualized by silver nitrate staining. Staining with alkaline phosphatase and silver nitrate permitted us to demonstrate the presence of osteocytic differentiation in the induced MSC culture (Figure 2).

In the present study we isolated a cell
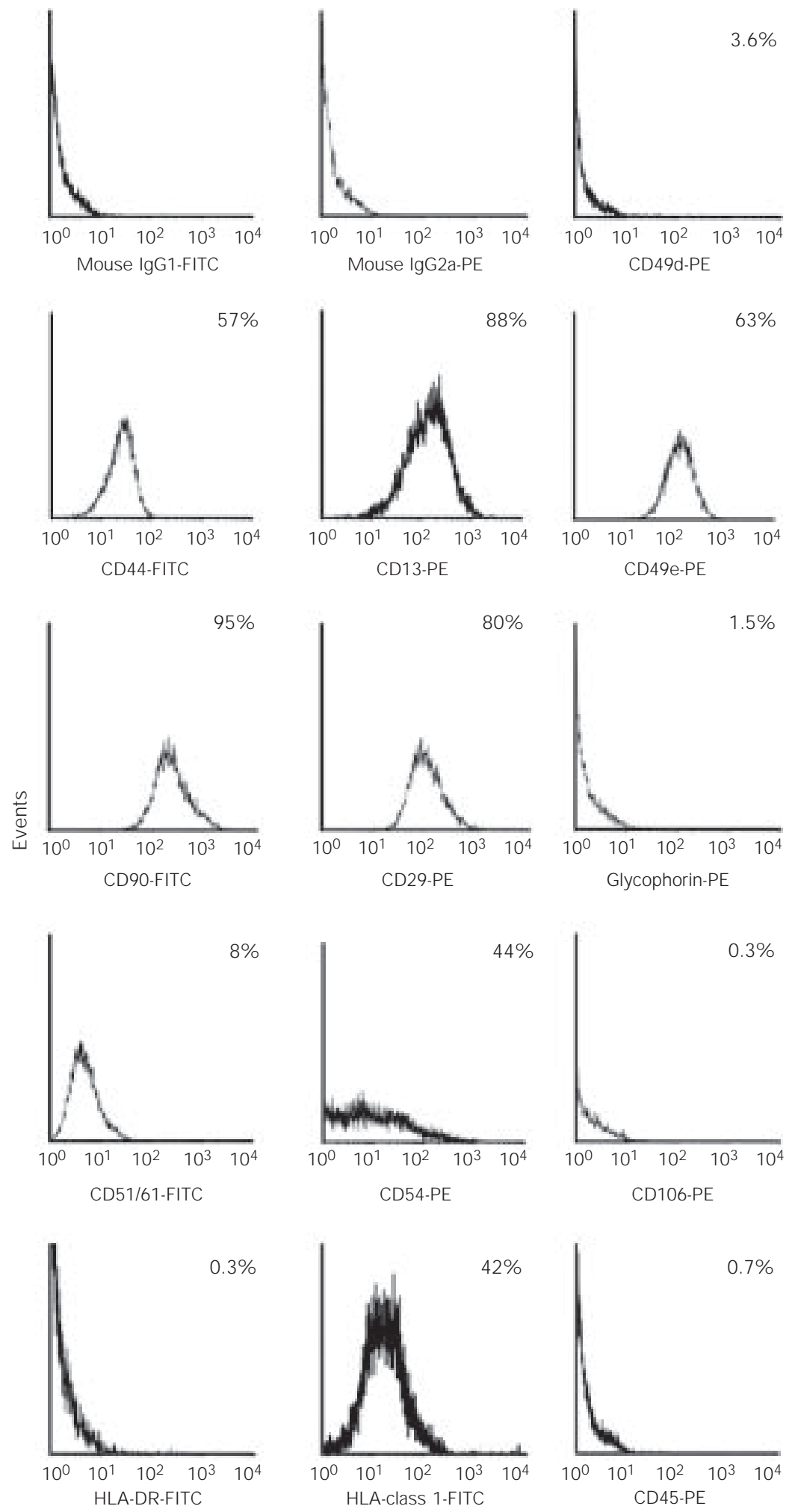

Figure 1. Flow cytometry histograms showing the immunophenotype of umbilical vein mesenchymal stem cells. The cells expressed CD13, CD90, CD29, CD44, CD49e, CD54 and HLA-class 1 . The percent positivity of each marker is indicated. 
Figure 2. Morphology and differentiation of umbilical cord vein mesenchymal stem cells (MSC). A,B, Fibroblastoid morphological aspect of MSC observed by phase microscopy. $C, D$, Fatty differentiation showing nonstimulated $(C)$ and stimulated (D) cells stained with Sudan III. The adipocytes present deeply stained fatty granules. E-H, Osteogenic differentiation showing nonstimulated ( $\mathrm{E}$ and $\mathrm{G}$ ) and stimulated ( $\mathrm{F}$ and $\mathrm{H})$ cells stained with alkaline phosphatase $(E, F)$ and with the von Kossa dye $(\mathrm{G}, \mathrm{H})$. The osteocytes are deeply stained. $A$ : 100X. B-H: 400X.
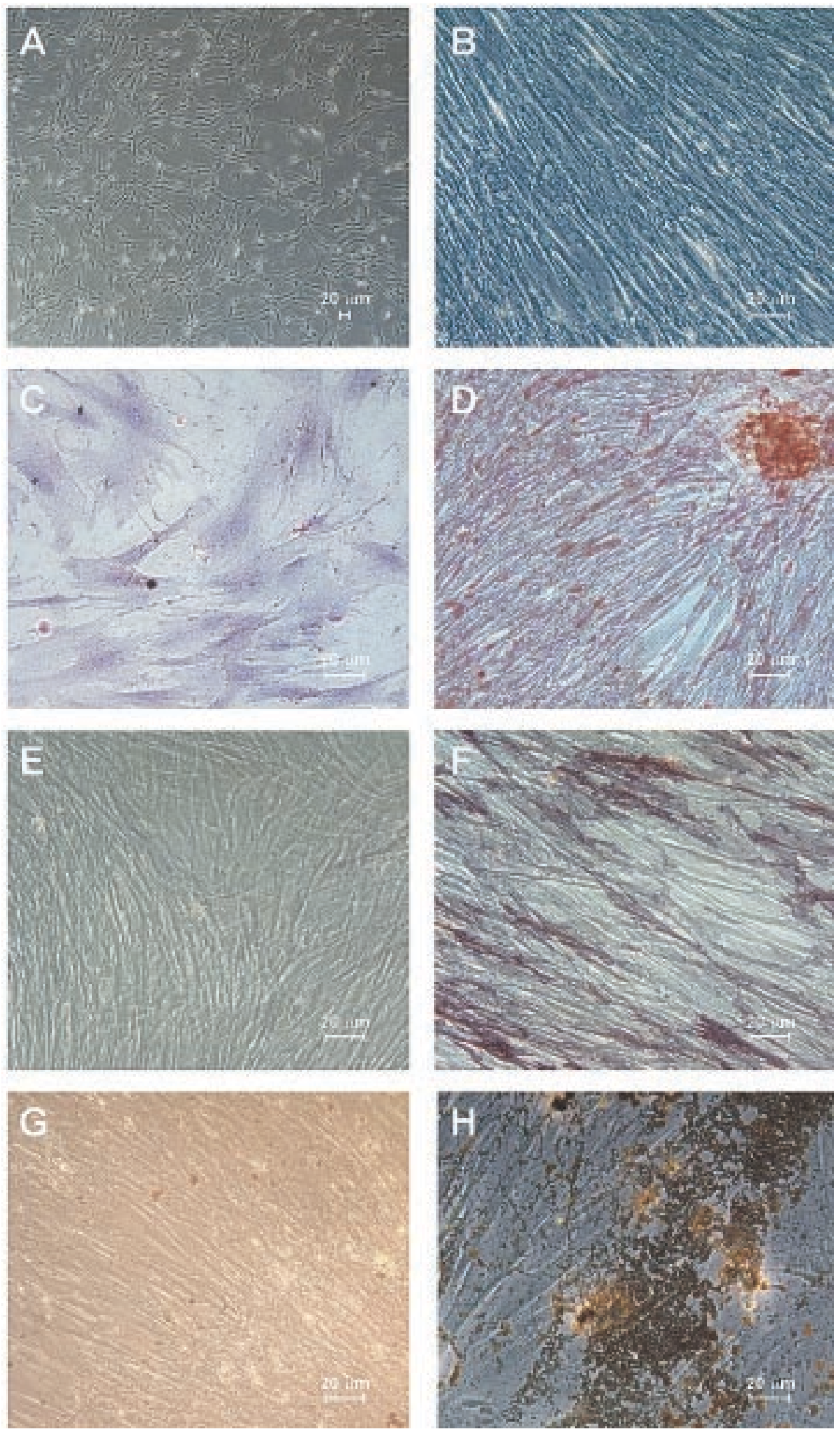
population derived from the endothelium or subendothelium of the umbilical cord vein with morphological, immunophenotypical and differentiation characteristics similar to those of MSC obtained from BM and originally described by Friedenstein et al. (3). This is the first time that cells with these characteristics isolated from the endothelium or subendothelium of the human umbilical vein are extensively characterized from an immunophenotypical viewpoint. The immunophenotypical and morphological profile of these cells is the same as that of MSC isolated from BM $(11,12)$. Romanov et al. (13) recently described cells isolated from the endothelium and subendothelium of the umbilical cord morphologically similar to those isolated here and also showing the ability of adipogenic and osteogenic differentiation. Although the biochemical markers used by these investigators were different from those employed in the present study, the cell type is probably the same in view of the similarities described, including cell adherence and fibroblastoid morphology. Additional studies are needed for further characterization of the pluripotentiality of these cells in view of the pluripotentiality of BMderived MSC (2). The umbilical cord, in addition to containing hematopoietic stem cells, seems to also be an important source of MSC, a fact indicating the possibility of its use in cell therapy protocols.

\section{References}

1. Minguell J J , Conget P \& Erices A (2000). Biology and clinical utilization of mesenchymal progenitor cells. Brazilian J oumal of Medical and Biological Research, 33: 881-887.

2. Caplan AI \& Bruder SP (2001). Mesenchymal stem cells: building blocks for molecular medicine in the 21st century. Trends in Molecular Medicine, 7: 259-264.

3. Friedenstein AJ , Gorskaja J F \& Kulagina NN (1976). Fibroblast precursors in normal and irradiated mouse hematopoietic organs. Experimental Hematology, 4: 267-274.

4. Kuznetsov SA, Friedenstein AJ \& Robey PG (1997). Factors required for bone marrow fibroblast colony formation in vitro. British J ournal of Haematology, 97: 561-570.

5. Caplan Al (1994). The mesengenic process. Clinics in Plastic Surgery, 21: 429-435.

6. Minguell J J , Erices A \& Conget P (2001). Mesenchymal stem cells. Experimental Biology and Medicine, 226: 507-520.

7. Campagnoli C, Roberts IA, Kumar S, Bennett PR, Bellantuono I \& Fisk NM (2001). Identification of mesenchymal stem/progenitor cells in human first-trimester fetal blood, liver and bone marrow. Blood, 98: 2396-2402.

8. Erices A, Conget P\& Minguell J J (2000). Mesenchymal progenitor cells in human umbilical cord blood. British J oumal of Haematology, 109: 235-242.

9. Mareschi K, Biasin E, Piacibello W, Aglietta M, Madon E \& Faioli F (2001). Isolation of human mesenchymal stem cells: bone marrow versus umbilical cord blood. Haematologica, 86: 1099-1100.

10. Wexler SA, Donaldson C, Denning-Kendall P, Rice C, Bradley B \& Hows J M (2003). Adult bone marrow is a rich source of human mesenchymal stem cells but umbilical cord and mobilized adult blood are not. British J oumal of Haematology, 121: 368-374.

11. Majumdar MK, Thiede MA, Mosca JD, Moorman M \& Gerson SL (1998). Phenotypic and functional comparison of cultures of marrow-derived mesenchymal stem cells (MSC) and stromal cells. J ournal of Cellular Physiology, 176: 57-66.

12. Conget PA \& Minguell JJ (1999). Phenotypical and functional properties of human bone marrow mesenchymal progenitor cells. J ournal of Cellular Physiology, 181: 67-73.

13. Romanov YA, Svintsitskaya VA \& Smimov VN (2003). Searching for altemative sources of postnatal human mesenchymal stem cells: candidate MSC-like cells from umbilical cord. Stem Cells, 21: 105110. 